\title{
Spatial variation of plant species richness in a sand dune field of northeastern Inner Mongolia, China
}

\author{
WU Jing ${ }^{1,2}$, QIAN Jianqiang ${ }^{2}$, HOU Xianzhang ${ }^{1}$, Carlos A BUSSO $^{3}$, LIU Zhimin ${ }^{2 *}$, XING \\ Baozhen $^{1}$ \\ ${ }^{1}$ Liaoning Forestry Vocation-Technical College, Shenyang 110164, China; \\ ${ }^{2}$ State Key Laboratory of Forest and Soil Ecology, Institute of Applied Ecology, Chinese Academy of Sciences, Shenyang \\ 110016, China; \\ ${ }^{3}$ Department of Agronomy, National University of the South and CERZOS (CONICET), Bahía Blanca 8000, Argentina
}

\begin{abstract}
Species richness is an important indicator of species diversity. Different sampling intensities will very likely produce different species richness values. Substantial efforts have already been made to explicitly quantify the spatial variability of soil properties in different ecosystems. However, concerns still remain on how to characterize the effect of different sampling intensities on plant species richness within a given region. This study characterized the spatial variability of plant species richness and the species distribution pattern in a $25-\mathrm{hm}^{2}$ sand dune plot in northeastern Inner Mongolia, China by using an intense sampling method $(n=10,000)$. We also evaluated the overall effect of information loss associated with the spatial variability and distribution patterns of species richness under various scenarios of sampling intensities ( $n=10,000$ to 289 ). Our results showed that semi-variograms of species richness were best described by the spherical and exponential models. As indicated by the nugget/sill ratio, species richness was different in terms of the strength of the spatial relationship. The different spatial metrics of species richness with increasing sampling intensities can represent different responses of the spatial patterns when compared with the reference set $(n=10,000)$. This study indicated that an appropriate sampling intensity should be taken into account in field samplings for evaluating species biodiversity properly. A sampling intensity of $n>2,500$ for species richness yielded satisfactory results to resemble the spatial pattern of the above-quantified reference set $(n=10,000)$ in this sand dune region of China.
\end{abstract}

Keywords: biodiversity; sampling intensity; semi-arid dune; spatial analysis; species richness

Citation: WU Jing, QIAN Jianqiang, HOU Xianzhang, Carlos A BUSSO, LIU Zhimin, XING Baozhen. 2016. Spatial variation of plant species richness in a sand dune field of northeastern Inner Mongolia, China. Journal of Arid Land, 8(3): 434-442. doi: 10.1007/s40333-016-0001-3

Spatial heterogeneity has been recognized as a dominant and conspicuous feature of ecological communities (Holmes et al., 2005). Previous studies on spatial heterogeneity at different scales revealed that heterogeneity of species is closely linked to species coexistence and competition patterns, population recruitment and vegetation succession (Gross et al., 1995; Gallardo et al., 2000). Also, in arid and semi-arid lands, vegetation often presents a distribution pattern of two phases: patches of vegetation and inter-patches of soil without vegetation (Busso et al., 2012). The greater the sampling intensity, the higher will be the possibility of identifying this pattern of vegetation distribution in space. This is, different sampling intensities (spatial scales) will probably produce different survey resolutions, which will lead to differences in vegetation information: greater sampling intensities (i.e. sampling scales) may lead to a more heterogeneous

*Corresponding author: LIU Zhimin (E-mail: zmliu@iae.ac.cn)

Received 2015-08-08; revised 2015-10-16; accepted 2015-10-30

(C) Xinjiang Institute of Ecology and Geography, Chinese Academy of Sciences, Science Press and Springer-Verlag Berlin Heidelberg 2016 
distribution of vegetation in space. Determining the appropriate sampling size is essential to ensure the reliability of collected data (Confalonieri et al., 2009). Within plot scales of a few meters, some studies use high sampling densities to describe the spatial variability of soil properties and vegetation parameters (Confalonieri et al., 2009; Heim et al., 2009). For instance, Gallardo (2003) used intensive sampling (i.e. 541 samples $/ \mathrm{hm}^{2}$ ) in a $1-\mathrm{hm}^{2}$ floodplain forest in Spain, and Wang et al. (2007) used 400 samples $/ \mathrm{hm}^{2}$ in a $90-\mathrm{hm}^{2}$ subtropical forest in southwestern China. However, the application of high sampling intensities is often of high cost and labor-consuming at large regional scales. On the other hand, some studies have relied on low sampling intensities to characterize the spatial patterns in other ecosystems. For example, Lopez-Granados et al. (2002) collected 84 and 80 soil samples in two plots (one was $6 \mathrm{hm}^{2}$, and another was $11.2 \mathrm{hm}^{2}$ ) to identify the spatial distribution of soil nutrients for implementing fertilization practices in southern Spain. However, the sparse and site-specific soil samplings might be too simplistic to characterize the complex spatial patterns of vegetation (Grunwald et al., 2007a). Therefore, quantifying vegetation parameters at different scales is essential for designing appropriate sampling schemes, and developing an accurate vegetation information dataset.

Geostatistical analysis is now considered as an appropriate method to estimate the value of vegetation variables at a large regional or even global scale. It can be specially used to fill data gaps on un-sampled sites. Geostatistical analysis focuses on detecting and estimating the spatial patterns of regional variables, and it concerns with modeling and interpreting semi-variograms. Semi-variogram models can distinguish the variation in measurements separated by a given distance, and provide the necessary information for Kriging (Webster, 1985). The spatial range of semi-variogram is an important index for describing the relatedness among measurements. It indicates that points close to one another tend to have similar values, whereas those that are far apart differ much for a specific parameter (Webster and Oliver, 2001). For example, substantial efforts have been made to explicitly quantify the spatial variability of soil nutrients in different ecosystems. Some studies have focused on characterizing soil nutrients along gradients (transects) expected to differ in this parameter (Garten et al., 2007; Wang et al., 2007). Other studies characterized the variability of soil nutrients at various spatial scales in different geographic regions (Lin et al., 2005; Diekmann et al., 2007). However, the variability of vegetation at various spatial scales has not been fully explored. Few studies can provide insights into the spatial variability of species richness based on an either reduced or large sampling effort in a given site. In other words, knowledge on the difference of spatial patterns of species richness along trajectories of more or less sparse observation sets is still limited.

In the present study, we investigated plant species richness using the grid method. It consisted of 10,000 quadrats in a $25-\mathrm{hm}^{2}$ plot in the sand dune field of northeastern Inner Mongolia, China. Plant species richness was analyzed to describe its distribution pattern. The objectives of this study were to (1) characterize the spatial variability of species richness across the study area with small and large observation sets; and (2) evaluate the information loss associated with the underlying spatial autocorrelation and spatial variability in species richness under various scenarios of sampling intensity.

\section{Materials and methods}

\subsection{Study area}

This study was conducted in the Wulanaodu region $\left(42^{\circ} 29^{\prime}-43^{\circ} 06^{\prime} \mathrm{N}, 119^{\circ} 39^{\prime}-120^{\circ} 02^{\prime} \mathrm{E} ; 480 \mathrm{~m}\right.$ asl), northeastern Inner Mongolia, China. The region has a semi-arid climate. The annual average temperature is $6.3^{\circ} \mathrm{C}$. The average annual precipitation is $340 \mathrm{~mm}, 70 \%$ of which occurs during the growing season. The growing season lasts from late April to late September. The area has been intensively grazed approximately since 1950. Over-grazing is the major reason for grassland degradation and desertification (Li et al., 2000). At present, desertified land accounts for $90 \%$ of the whole land area in the region ( $\mathrm{Li}$ et al., 2000). Active sand dunes, which are 15-35 $\mathrm{m}$ heights, are heterogeneously distributed in this region. These dunes advance at a speed of ca. 6-7 m/a. The original vegetation was sparse elm woodland, which included perennial grasses such as 
Phragmites communis and Calamagrostis epigeios. This vegetation has been altered in the past several decades because of continued overcutting and overgrazing and the desertification process (Cao et al., 2011). The present vegetation is mainly dominated by some shrubs, such as Salix gordejevii, Artemisia halodendron, A. wudanica, and perennial and annual herbs, such as Aristida adscensionis, Agriophyllum squarrosum and Setaria viridis (Cao et al., 2011).

\subsection{Field investigation}

One $25-\mathrm{hm}^{2}$ (500 m×500 m; Fig. 1a) plot having 14 inter-dune lowlands of different sizes (ranging from 0.03 to $1.03 \mathrm{hm}^{2}$; Fig. 1a) was established in 2010. Plot area was measured with a GPS. During the period from June to September in 2010, by using a grid sampling method (Fig. 1b), repeated investigations were conducted at different scales to evaluate species richness in the study region. During the investigation, horizontal and vertical transects were established in the 500 $\mathrm{m} \times 500 \mathrm{~m}$ plot every either $5,10,15,20,25$ or $30 \mathrm{~m}$. Then, a $1 \mathrm{~m} \times 1 \mathrm{~m}$ quadrat was randomly spread within each of the study transects to investigate species richness. For the $5 \mathrm{~m} \times 5 \mathrm{~m}, 10 \mathrm{~m} \times 10 \mathrm{~m}, 15$ $\mathrm{m} \times 15 \mathrm{~m}, 20 \mathrm{~m} \times 20 \mathrm{~m}, 25 \mathrm{~m} \times 25 \mathrm{~m}$ and $30 \mathrm{~m} \times 30 \mathrm{~m}$ sampling resolutions, the numbers of vegetation quadrats $(n)$ were $10,000,2,500,1,156,625,400$ and 289 , respectively. For example, if we take the $5 \mathrm{~m} \times 5 \mathrm{~m}$ sampling resolution in the $500 \mathrm{~m} \times 500 \mathrm{~m}$ plot, there were 100 horizontal $(500 \mathrm{~m}$ divided by $5 \mathrm{~m}$ ) and 100 vertical transects, giving a total of 10,000 quadrats (i.e. $100 \times 100)$. At the other extreme, in the $30 \mathrm{~m} \times 30 \mathrm{~m}$ sampling resolution in the study plot, there were 17 horizontal $(500 \mathrm{~m}$ divided by $30 \mathrm{~m})$ and 17 vertical transects, leading to $(17 \times 17) 289$ quadrats.

(a)

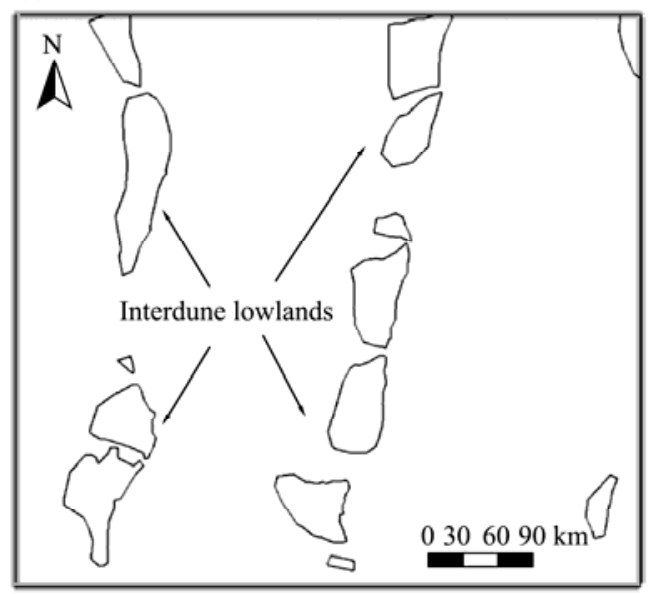

(b)

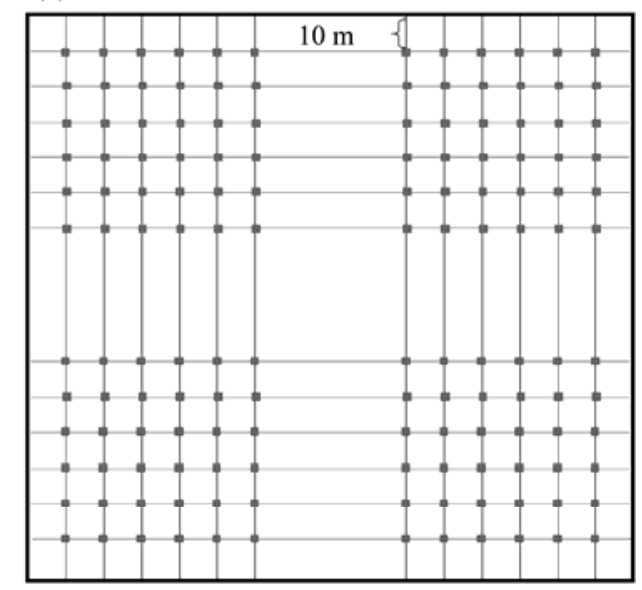

Fig. 1 Study plot $(500 \mathrm{~m} \times 500 \mathrm{~m})$ showing the inter-dune lowlands (a). These are represented by the areas within the solid lines. These have been drawn to a scale, ranging from 0.3 to $1.2 \mathrm{hm}^{2}$. The study plot was divided by horizontal and vertical lines every $10 \mathrm{~m}$ (b). Only some lines are shown as an example. Otherwise, 50 lines (i.e. $500 / 10 \mathrm{~m})$ should have been drawn both horizontally and vertically $(n=50 \times 50=2,500)$ if they were separated at 10 $\mathrm{m}$ from one another in the study plot.

\subsection{Geostatistical analyses}

We used the total data set of 10,000 sample sites to derive the semi-variograms of species richness. Detrended analysis and the corresponding semi-variograms for residuals were performed. Detrended analysis was used because a large spatial trend in the data across the site may violate the stationarity assumption. Trend can be thought of as a pattern whose dimensions are larger than the sampling space and/or significant lag classes. Because of the trends, the local mean and variance will be different with location and direction. The directional effects may cause a large-scale trend because the effects of some processes should decrease with increasing distance. This large-scale trend, if reflected in the semi-variogram, may mask small-scale structures in the data. Thus, the presence of a large-scale trend is removed by detrending, which is accomplished by fitting a regression to the trend, and using only the residuals for semi-variance analysis. This residual reflects the local spatial dependency. We paid much attention to the spherical model, which has been proven 
especially useful in the interpretation of soil data (Krasilnikov et al., 2008). Envelopes were computed for empirical variograms by permutation of the data values on the spatial locations. For each of the 99 simulations, data values were randomly allocated to spatial locations. We used the same lags when semi-variograms were computed for each simulation than when they were originally computed for the data. The envelopes were computed by taking the maximum and minimum values of semi-variograms for the simulated data at each lag. Semi-variogram estimations were above or below the envelop boundaries, indicating the presence of a spatial pattern at the spatial scale. We obtained spatial predictions by using ordinary Kriging with a block size of $10 \mathrm{~m}$ $\times 10 \mathrm{~m}$ across the study area. For evaluating the effect of using a reduced data set to represent the underlying spatial variability and distribution of species richness, we selected the subsets of 2,500, $1,156,625,400$ and 289 observation sites from the total sampling points (i.e. $n=10,000$ ) in the 500 $\mathrm{m} \times 500 \mathrm{~m}$ study area. The semi-variograms of species richness were computed and predicted using ordinary kriging. We used the mean prediction error (MPE) and the root mean square error (RMSE), to evaluate the model performance as a validation mode for species richness (Webster and Oliver, 2001). The MPE and RMSE were defined as:

$$
\mathrm{MPE}=\frac{1}{n} \sum_{j=1}^{n} Z_{j}-Z_{j}, \quad \text { (1) } \quad \mathrm{RMSE}=\frac{1}{\bar{Z}} \sqrt{\frac{1}{n} \sum_{j=1}^{n}\left(Z_{j}-Z_{j}\right)^{2}} .
$$

Where MPE was the mean prediction error, and RMSE was the root mean square error; $Z_{j}$ was the estimated data, $z_{j}$ was the actual data, and $\bar{Z}$ was the sample mean value. We further assumed that the intensive sampling observation model $(n=10,000)$, which from now on will be called the reference model, was the most accurate among the considered sampling efforts. A misclassification rate was calculated as the deviation of the reference model from the reference probabilities for each subset $(n=2,500,1,156,625,400$ and 289). All geostatistical analyses were performed with R 2.8.0 (R Development Core Team, 2008), using the geoR modules (Ribeiro and Diggle, 2001).

\section{Results}

\subsection{Semi-variogram metrics of species richness for different sampling intensities}

The exponential and spherical models showed a nugget variance of 0.173 , sill variance of 0.344 , and range of $11 \mathrm{~m}(n=10,000)$ (Table 1). When the exponential model was used to fit the empirical semi-variogram of species richness, the (1) nugget variance was 0.139 , (2) sill variance was 0.334 , and the range was $13 \mathrm{~m}(n=2,500)$. As indicated by the increased nugget variance, nugget/sill ratio and range at the less intensive samplings, the spatial relationship of species richness became weaker when sampling intensities were reduced $(n=1,156-289)$. This is, species richness exhibited a significant spatial dependence under the denser sampling intensities $(n=10,000-2,500)$. While the range increased abruptly at lower sampling intensities $(n=1,156-289)$, there was no significant differences in the range when sampling intensities varied from $n=2,500$ to 10,000 .

\subsection{Semi-variogram and prediction of species richness for different sampling intensities}

The semi-variograms of species richness under anisotropy exhibited excellent spatial pattern, with semi-variogram points below the lower boundary of the envelope at the sparser sampling intensities ( $n=289$ to 400 ) (Fig. 2). In this case, the fraction of the total variance explained by the spatial dependence (Nugget/sill) ranged between 0.714 and 0.785 (Table 1). On the other hand, the semi-variograms of species richness under anisotropy exhibited a much slighter spatial pattern at higher sampling intensities $(n=625$ to 10,000$)$, with the semi-variogram points being below the lower boundary of the envelope at the sparser sampling intensities. The fraction of the total variance explained by spatial dependence (Nugget/sill) ranged between 0.500 and 0.721 at the 10,000 and 625 sampling intensities, respectively (Table 1). 
Table 1 Pooled semi-variogram metrics of species richness based on 50 iterations for different sampling intensities

\begin{tabular}{|c|c|c|c|c|c|}
\hline $\begin{array}{l}\text { Sampling } \\
\text { intensity }(n)\end{array}$ & Nugget & Sill & Nugget/sill & $\begin{array}{l}\text { Spatial } \\
\text { dependence }\end{array}$ & $\begin{array}{c}\text { Range } \\
\text { (m) }\end{array}$ \\
\hline 10,000 & 0.173 & 0.344 & 0.500 & Significant & 11.0 \\
\hline 2,500 & 0.139 & 0.334 & 0.416 & Significant & 13.0 \\
\hline 1,156 & 0.282 & 0.354 & 0.796 & Weak & 67.6 \\
\hline 625 & 0.245 & 0.340 & 0.721 & Moderate & 56.8 \\
\hline 400 & 0.249 & 0.316 & 0.785 & Weak & 66.7 \\
\hline 289 & 0.247 & 0.346 & 0.714 & Moderate & 72.7 \\
\hline
\end{tabular}
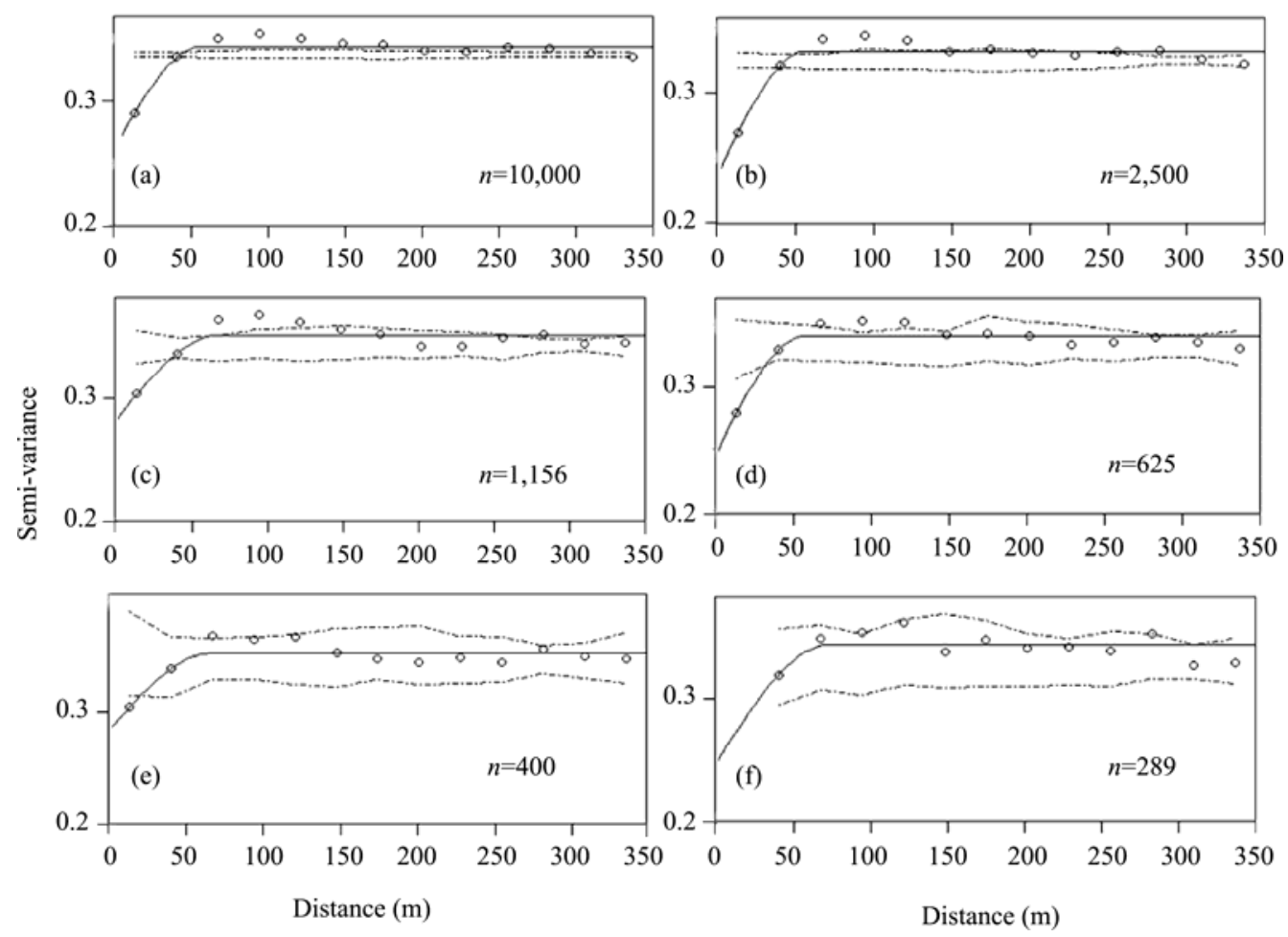

Fig. 2 Semi-variograms of species richness for different sampling intensities. Note the change of scale in the $y$ axis.

\subsection{Kriging information of species richness at different sampling intensities}

Figure 3 showed the mean spatial distribution patterns of species richness for various subsets based on 50 iterations $(n=2,500-289)$ Although regional high and low values of species richness existed in all Figs. 3a-f, spatial patterns disintegrated slightly under reduced sampling intensities (Fig. 3). Kriging result of species richness showed a more detailed spatial pattern at the more intense sampling intensity. Spatial patterns tended to be more homogeneous with a reduced sampling intensity (Fig. 3).

\subsection{Validation for different sampling intensities}

The validation showed larger MPE and RMSE values for species richness with reduced sampling intensities ( $n=2,500-289)$ (Table 2). The MPE and the RMSE were $313 \%$ and $257 \%$ higher, respectively, in the sparser $(n=289)$ than in the denser sample set $(n=10,000)$. 

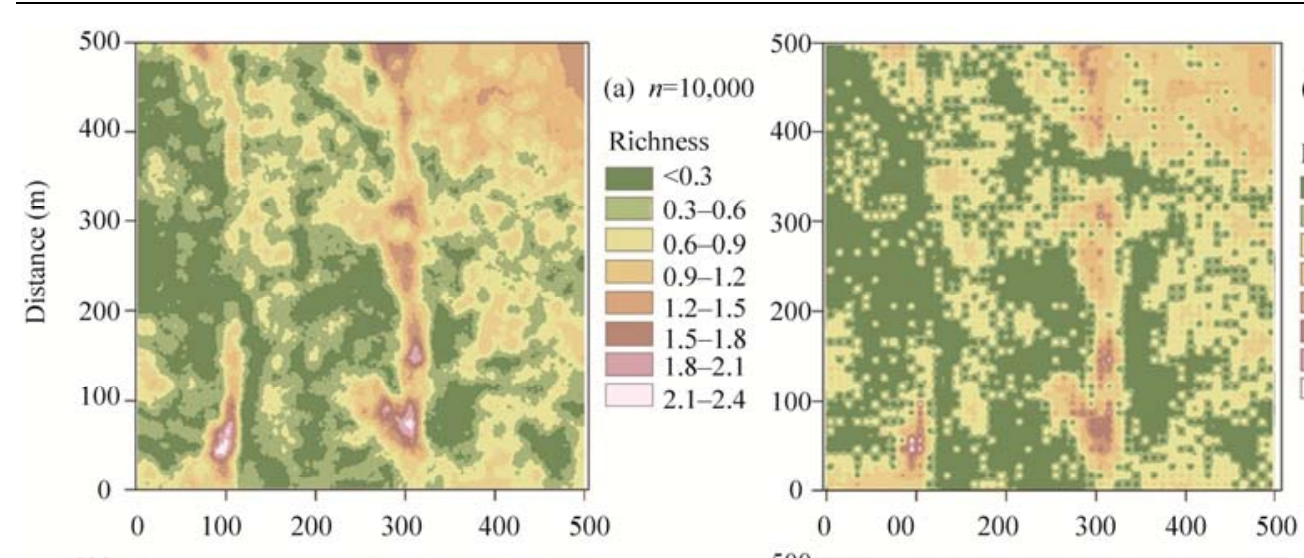

(b) $n=2,500$

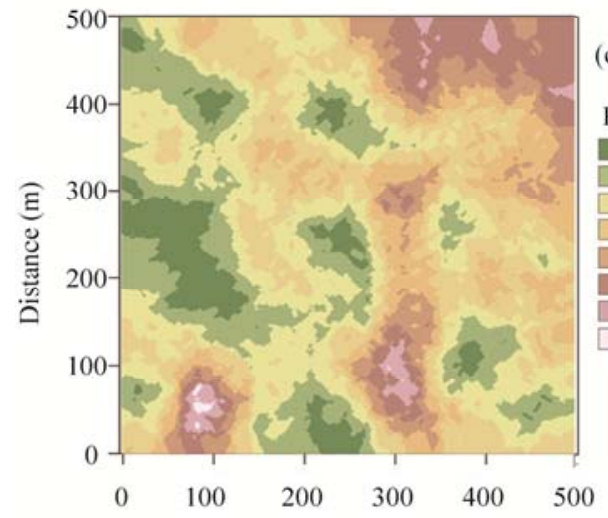

(c) $n=1,156$
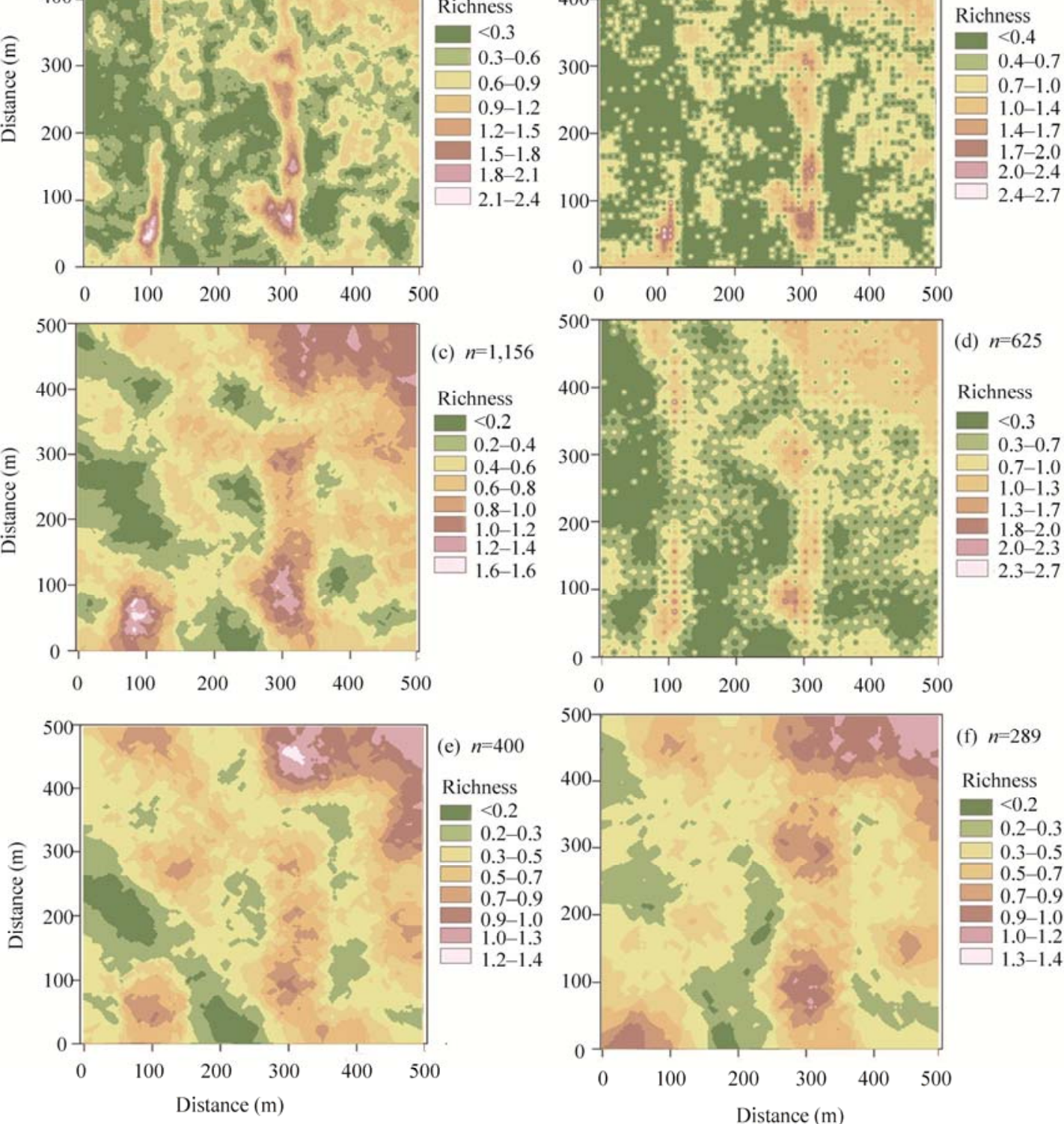

Fig. 3 Kriging interpolation of species richness for different sampling intensities. Note the change in the range of species richness at the same color shading among the various intensities.

Table 2 The MPE and RMSE of species richness for different sampling intensities based on 50 iterations

\begin{tabular}{lcccccc}
\hline \multirow{2}{*}{ Item } & \multicolumn{5}{c}{ Sampling intensity $(n)$} \\
\cline { 2 - 7 } & 10,000 & 2,500 & 1,156 & 625 & 400 & 289 \\
\hline MPE & 0.015 & 0.016 & 0.018 & 0.039 & 0.068 & 0.047 \\
RMSE & 0.217 & 0.259 & 0.315 & 0.531 & 0.919 & 0.559 \\
\hline
\end{tabular}

\section{Discussion}

The application of geostatistics to study spatial variability is fairly common (Goovaerts, 1997). However, relatively few studies have provided high-resolution analyses of the spatial dependency of vegetation information at various sampling intensities (e.g. $n$ from 289 to 10,000) in the sand 
dune region. Our study provided use of a relative high sampling set $(n=10,000)$, and captured the spatial variability at a broad set of scales which facilitated a relative accurate geostatistical analysis and Kriged map.

The disintegration of spatial patterns under the reduced sampling intensity did not express the heterogeneity in species richness. Species richness showed a greater heterogeneity at the fine-scale spatial patterns, when denser sampling intensities were used (e.g. $n=10,000$ and 2,500). This was because of their short spatial autocorrelations of 11 and $13 \mathrm{~m}$, respectively (Table 1). The spatial autocorrelation range of species richness at the lower sampling intensities changed from $67.6(n=1,156)$ to $56.8(n=625), 66.7(n=400)$ or $72.7 \mathrm{~m}(n=289)$. The strength of the spatial relationship was relative stable for observation sets between 10,000 and 2,500, but started to decrease dramatically for $n<2,500$. This suggests that the spatial relationship for species richness was not represented adequately using observations sets smaller than $n=2,500$.

We showed that the range and the nugget/sill ratio of species richness both increased from a higher to a lower sampling intensity. Our results suggest that a greater spatial variability in species richness can be achieved at higher than lower sampling intensities. This seems reasonable because the distance among sampling points increases as sampling intensity decreases, resulting in a loss of information at finer scales (i.e. increasing sampling intensities). However, the range and nugget/sill ratio did not increase linearly with reduced sampling intensities; the variability was higher at the finer than coarser spatial scales. Commonly, the nugget/sill ratio was low, suggesting that part of the total variance was either random variation (as a result of random field and laboratory sampling errors) or variability at scales smaller than the greatest study sampling intensity (i.e. $n=10,000$ ) (Goovaerts, 1997; Webster and Oliver, 2001).

As with any sampling scheme, a trade-off exists between the number of samples required and the desired sampling precision. Also the number of samples collected and analyzed is directly related to costs associated with verification (Conant and Paustian, 2002). Optimized sampling schemes are required for any given study area. This is to provide insights to the spatial response of various biogeochemical patterns that should be taken into account not only the short but also the long-range variability (Grunwald and Reddy, 2008). The spatial response of species richness was very different in the sand dune region. Grunwald et al. (2007b) suggested that they could separate biogeochemical indicator variables based on the spatial variability and response. This has implications for field sampling in terms of making an appropriate sampling intensity to present a given biogeochemical indicator variable.

We observed that the distribution pattern of vegetation was scale-dependent. Vegetation heterogeneity increased as sampling intensity also increased (Fig. 3). These results have implications on the ecology of arid and semi-arid areas. Scale is a key component for quantifying species richness, a component of biological diversity (Huston, 1998). This is due to the interactions and processes that are related with this diversity can vary as a function of the level of study in which is carried out (Qian and Ricklefs, 2000). At the landscape level, the heterogeneity of grasslands is generally determined by the differentiation between communities through the environmental gradients, which are associated to topography, drainage system, and physical-chemical properties of soil or complex combinations of these variables (Ovalle et al., 2006). At the community level, there is a more or less gradual change in habitat conditions, which interacts with different biotic factors in the control of plant diversity (Soliveres and Maestre, 2014). In addition, there might also be an internal variability within grassland communities, which can be determined by subtle changes in topography, soil fertility and salinization, among others. As the extension and the grain observation reduced, the biological activity of plants acts decoupling the influence of abiotic factors on the vegetation (Huston, 1998).

Vegetation at the study area is rather heterogeneous, with plant patches interspersed within a matrix of uncovered, nude soil (Jiang et al., 2014). Since this kind of vegetation distribution is often found in various arid and semi-arid areas, it may be possible to replicate this study in those regions to optimize sampling intensity on investigations similar to that reported in our study. Also, the results of this study can be related to certain patterns of the ecology of semiarid ecosystems. For example, the spatial heterogeneity of vegetation and environmental conditions is one of the 
main features of arid and semi-arid ecosystems (Busso et al., 2012), which most often show a mosaic pattern, with patches of high biomass vegetation that are interspersed in a matrix of either poor vegetation or nude soil (Busso et al., 2012).

\section{Conclusions}

This study characterized the spatial variability and the response of species richness at various sampling intensities across a sand dune field in northeastern Inner Mongolia, China. Species richness was highly spatially structured, and spatial variations depended upon the sampling scale. Spatial patterns of species richness disintegrated dramatically at the lower than higher sampling intensities (e.g. when compared with the reference set $(n=10,000))$. In the study region, a sampling intensity of $n>2,500$ (or 34.8 samples $/ \mathrm{hm}^{2}$ ) will yield spatial patterns of species richness compared with much larger sampling intensities (e.g. $n=10,000)$.

\section{Acknowledgements}

This work was funded by the National Basic Research Program of China (2013CB429903). Author Carlos A BUSSO thanks the Third World Academy of Sciences (TWAS) for the associateship and the Institute of Applied Ecology, Chinese Academy of Sciences for covering all the expenses which allowed him to collaborate in this work. We acknowledge two anonymous reviewers whose suggestions greatly improved a previous version of this paper.

\section{References}

Busso C A, Bonvissuto G L, Torres Y A. 2012. Seedling recruitment and survival of two desert grasses in the Monte of Argentina. Land Degradation \& Development, 23(2): 116-129.

Cao C Y, Jiang S Y, Ying Z, et al. 2011. Spatial variability of soil nutrients and microbiological properties after the establishment of leguminous shrub Caragana microphylla Lam. Plantation on sand dune in the Horqin sandy land of Northeast China. Ecological Engineering, 37(10): 1467-1475.

Conant R T, Paustian K. 2002. Spatial variability of soil organic carbon in grasslands: implications for detecting change at different scales. Environmental Pollution, 116(Supp1.): S127-S135.

Confalonieri R, Perego A, Chiodini M E, et al. 2009. Analysis of sample size for variables related to plant, soil, and soil microbial respiration in a paddy rice field. Field Crops Research, 113(2): 125-130.

Diekmann L O, Lawrence D, Okin G S. 2007. Changes in the spatial variation of soil properties following shifting cultivation in a Mexican tropical dry forest. Biogeochemistry, 84(1): 99-113.

Gallardo A, Rodríguez-Saucedo J J, Covelo F, et al. 2000. Soil nitrogen heterogeneity in a Dehesa ecosystem. Plant and Soil, 222(1-2): 71-82.

Gallardo A. 2003. Spatial variability of soil properties in a floodplain forest in Northwest Spain. Ecosystem, 6(6): 564-576.

Garten C T Jr, Kang S, Brice D J, et al. 2007. Variability in soil properties at different spatial scales (1 m-1 km) in a deciduous forest ecosystem. Soil Biology and Biochemistry, 39(10): 2621-2627.

Goovaerts P. 1997. Geostatistics for Natural Resources Evaluation. New York: Oxford University Press.

Gross K L, Pregitzer K S, Burton A J. 1995. Spatial variation in nitrogen availability in three successional plant communities. Journal of Ecology, 83(3): 357-367.

Grunwald S, Rivero R L, Reddy K R. 2007a. Understanding spatial variability and its application to biogeochemistry analysis. Developments in Environmental Science, 5: 435-462.

Grunwald S, Reddy K R, Prenger J P, et al. 2007b. Modeling of the spatial variability of biogeochemical soil properties in a freshwater ecosystem. Ecological Modeling, 201(3-4): 521-535.

Grunwald S, Reddy K R. 2008. Spatial behavior of phosphorus and nitrogen in a subtropical wetland. Soil Science Society of America Journal, 72(4): 1174-1183.

Heim A, Wehrli L, Eugster W, et al. 2009. Effects of sampling design on the probability to detect soil carbon stock changes at the Swiss CarboEurope site Lägeren. Geoderma, 149(3-4): 347-354.

Holmes K W, Kyriakidis P C, Chadwick O A, et al. 2005. Multi-scale variability in tropical soil nutrients following land-cover change. Biogeochemistry, 74(2): 173-203.

Huston M A. 1998. Biological diversity. In: The Coexistence of Species in Changing Landscapes. Cambridge: Cambridge University Press. 
Jiang D M, Tang Y, Busso C A. 2014. Effects of vegetation cover on recruitment of Ulmus pumila L. in Horqin Sandy Land, northeastern China. Journal of Arid Land, 6(3): 343-351.

Krasilnikov P, Carré F, Montanarella L. 2008. Soil Geography and Geostatistics, Concepts and Applications. Luxembourg: Institute for Environment and Sustainability.

Li S G, Harazono Y, Oikawa T, et al. 2000. Grassland desertification by grazing and the resulting micrometeorological changes in Inner Mongolia. Agricultural and Forest Meteorology, 102(2-3): 125-137.

Lin H S, Wheeler D, Bell J, et al. 2005. Assessment of soil spatial variability at multiple scales. Ecological Modelling, 182(3-4): $271-290$

López-Granados F, Jurado-Expósito M, Atenciano S, et al. 2002. Spatial variability of agricultural soil parameters in southern Spain. Plant and Soil, 246(1): 97-105.

Ovalle C, Del Pozo A, Casado M A, et al. 2006. Consequences of landscape heterogeneity on grassland diversity and productivity in the espinal agroforestry system of central Chile. Landscape Ecology, 21(4): 585-594.

Qian H, Ricklefs R E. 2000. Large-scale processes and the Asian bias in species diversity of temperate plants. Nature, 407(6801): 180-182.

R Development Core Team. 2008. R: A Language and Environment for Statistical Computing. Vienna: Foundation for Statistical Computing.

Ribeiro P J Jr, Diggle P J. 2001. GeoR: a package for geostatistical analysis. R-NEWS, 1(2): 15-18.

Soliveres S, Maestre F T. 2014. Plant-plant interactions, environmental gradients and plant diversity: a global synthesis of community-level studies. Perspectives in Plant Ecology, Evolution and Systematics 16(4): 154-163.

Wang L X, Mou P P, Huang J H, et al. 2007. Spatial heterogeneity of soil nitrogen in a subtropical forest in china. Plant and Soil, 295(1-2): 137-150.

Webster R. 1985. Quantitative spatial analysis of soil in the field. In: Stewart B A. Advances in Soil Science. New York: Springer, 3: 1-70.

Webster R, Oliver M A. 2001. Geostatistics for Environmental Scientists. New York: John Wiley and Sons. 